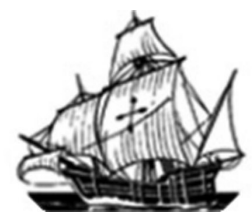

\title{
Ruy Duarte de Carvalho: caminhos de um poeta antropólogo
}

\author{
Laura Regina dos Santos Dela Valle ${ }^{1}$ \\ Orientadora: Prof ${ }^{\mathrm{a}}$. Dr ${ }^{\mathrm{a}}$ Ana Lúcia Liberato Tettamanzy
}

\begin{abstract}
Resumo: A relação interdisciplinar entre a literatura e a antropologia tem florescido na escrita contemporânea. Alguns autores constroem suas personagens com base em longas pesquisas etnográficas. As vozes anônimas ganham vida ao serem traduzidas pelas vozes autorizadas dos escritores modernos. Desse modo, a ficção se transforma em uma maneira de dizer o que se vê nas diferentes culturas. Ver, interpretar, traduzir o mundo: a experiência passou a ser a inspiração literária de muitos autores modernos, e, consequentemente, a discussão envolvendo literatura e antropologia tem crescido de maneira produtiva e está abrindo caminho para novos estudos envolvendo os dois campos. Um bom exemplo disso é a escrita do angolano Ruy Duarte de Carvalho, que mistura elementos etnográficos em sua obra literária. Sendo assim, o objetivo deste trabalho é mostrar como se configura essa relação nas obras Os papéis do inglês (2007) e Vou lá visitar pastores (2000). Em ambas o narrador-autor desde o início apresenta traços bio(biblio)gráficos inusitados. Cito como exemplo a constante retomada referencial de personagens que o acompanharam em suas "deambulações etnográficas" em Vou lá visitar pastores. Nessa obra o narrador/autor conta sua própria experiência antropológica e observa as experiências dos outros para contá-las à sua maneira. Observamos que o olhar de Ruy Duarte de Carvalho está voltado para os povos e as culturas africanas, tanto que, mesmo em Os papéis do inglês, a história desse ilustre representante do Ocidente adquire valor secundário no decorrer da obra. Duarte produz narrativas permeadas por questões de identidade, memória e autoria em que se alternam papéis assumidos ora por ele "mesmo", ora pelo "outro". Para tanto, além da leitura das obras citadas, consideraremos conceitos como tradição e modernidade e póscolonialismo a partir dos estudos de Laura Padilha, e discutiremos os pressupostos de James Clifford (2011) e Cliford Geertz (2009) sobre as aproximações entre antropologia e literatura.
\end{abstract}

Palavras-chave: literatura; antropologia; memória; narrativa; história.

\begin{abstract}
The interdisciplinary relationship between literature and anthropology has flourished in contemporary writing. Some authors build their characters based on long ethnographic research. The anonymous voices come alive when they are translated by the authoritative voices of the modern writers. Thus, the fiction becomes a way of saying what we see in different cultures. Seeing, interpreting, translating the world: the experience became the literary inspiration for many modern authors, and consequently, the discussion involving literature and anthropology has grown productively and is opening ways for new studies involving the two camps. A good example is the writing of an Angolan Ruy Duarte de Carvalho, mixing elements ethnographic in his literary work.

\footnotetext{
${ }^{1}$ Mestranda em Letras - Literaturas Portuguesa e Luso-Africanas pela UFRGS. (lsdelavalle@hotmail.com).
} 
Thus, the aim of this work is to show how to set up this relationship in the works of English papers (2007) and I'm going to visit pastors (2000). In both the narrator-author from the beginning shows unusual bibliographic traces. I cite as an example the constant referencial resumption of those characters that accompanied him on his "ethnographic wanderings "Vou lá visitar pastores". In this book the narrator /author tells his own anthropological experience and observe the experiences of the others to explain it with his own manners. We note that Ruy Duarte de Carvalho's look is turned to the peoples and cultures of Africa, so that even in "Os papéis do inglês", the history of this distinguished representative of the western civilization acquires secondary value throughout the work. Duarte produces narratives permeated by issues of identity, memory and authority in alternating roles assumed sometimes by "himself", other times by the "other". Therefore, in addition to reading the works cited, we will consider concepts like tradition and modernity and post-colonialism from the studies of Laura Padilla, and discuss the assumptions of James Clifford (2011) and Clifford Geertz (2009) on the proximities of anthropology and literature.

Keywords: literature; antropology; memory; narrative; history.

"Os que nunca acreditaram que eu andasse por aqui a fazer só antropologias tinham finalmente razão."

Ruy Duarte de Carvalho

A literatura, na contemporaneidade, tem nos permitido trilhar caminhos inusitados e relevantes para a discussão interdisciplinar entre ela e outras áreas do saber. Nesse contexto é que se insere a obra do angolano Ruy Duarte de Carvalho, pois sua construção narrativa nos fornece um rico manancial em que dialogam literatura e antropologia em um processo híbrido. Nesse processo a história e a geografia são fontes que ilustram e amarram a teia narrativa. Podemos dizer que a "ficção realista" proposta pelo autor não representa o cenário de um mundo imaginado, mas um espaço fisicamente experimentado. "É a imaginação que cria, servindo-se do real como matéria" (HISSA, 2002, p. 118).

O que Ruy Duarte faz é explorar as inúmeras potencialidades que a autoridade etnográfica dispõe em prol do processo de construção da narrativa. Suas diferentes leituras da paisagem resultam num texto híbrido e extenso, escrito entre espaços remanescentes da colonização portuguesa: entre impressão e percepção, olhar e representação, literatura e antropologia, estória e história; 
espaços labirínticos que tentaremos desvendar percorrendo os caminhos do poeta/antropólogo.

Ao discutir o fazer literário e introduzir elementos etnográficos em sua obra, Ruy Duarte cria uma estrutura inovadora que desafia os padrões institucionalizados, mas, ou seja, cria estratégias que se adequam bem aos desafios contemporâneos. Isso pode ser pensado tanto para a Literatura quanto para a Antropologia, pois o olhar do autor sobre o "outro" está de acordo com o que defende James Clifford (2011). Ambos vêm o estudo etnográfico pela imaginação generalizada, completamente democrática, não traduzindo apenas o olhar Ocidentalizado.

O espaço angolano é o universo particular escolhido por Ruy Duarte de Carvalho para vivenciar e experimentar histórias, memórias e sonhos. As intervenções desse narrador podem ser observadas, entre outras obras, em Vou lá visitar pastores (1999) e Os papéis do inglês (2007). Nessas obras o autor/narrador revela a si mesmo como um sujeito que transita por múltiplos espaços, e, ao narrar a história do povo que escolheu como seu, também narrou sua própria experiência como escritor, professor e antropólogo.

Ruy Duarte nasceu em Portugal em 1941, foi para Angola ainda criança e naturalizou-se angolano em 1975. Faleceu em 2009, aos 69 anos, na Namíbia, onde residia. Como antropólogo, investigou as sociedades pastoris e agropastoris do sudoeste de Angola e do noroeste da Namíbia. Como escritor publicou ensaios, narrativas e poemas. Na ficção, publicou os livros Vou lá visitar pastores (1999), Actas da Maianga (2003), Os Papéis do Inglês, As paisagens Propícias (2005), Desmedida (2007), que ganhou o Prêmio Literário Casino da Póvoa, e $A$ Terceira Metade (2009), todos na Cotovia. No Brasil, publicou Os Papéis do Inglês (Companhia das Letras) e Desmedida (Língua Geral). Além disso, produziu inúmeros filmes sobre os povos do sul de Angola. 
É possível perceber que ele revela a voz do "Outro" para mostrar uma versão distinta da história da África internalizada na memória do mundo pelo olhar do colonizador: "Prefiro vir a falar-te dessa guerra a partir da memória que os próprios Kuvale guardam da punição que sofreram (...)" (CARVALHO, 2000, p.53). No excerto retirado do livro Vou lá visitar pastores o autor está se dirigindo a um repórter da $\mathrm{BBC}$, seu amigo, que combinou ir encontrá-lo para acompanhá-lo em suas deambulações pelo deserto, no Sul de Angola. Como o amigo demorou a chegar Duarte decidiu gravar fitas cassetes para que ele se situasse ao passar pelos caminhos já percorridos pelo autor.

Ao narrar a vida do povo Kuvale para seu interlocutor/ouvinte, Ruy Duarte vai desconstruindo a imagem ocidentalizada que o amigo, porventura, pudesse ter, e segue produzindo uma nova visão desse "Outro", onde o que importa é a versão nativa em relação à sua própria história. Sobre essa desconstrução James Clifford afirma que :

Após a reversão do olhar europeu em decorrência do movimento da "negritude", após a crise de conscience da antropologia em relação ao seu status liberal no contexto da ordem imperialista, e agora que o Ocidente não pode mais se apresentar como o único provedor de conhecimento antropológico sobre o outro, tornou-se necessário imaginar um mundo de etnografia generalizada. (CLIFFORD, 2011, p.18).

O movimento da negritude, descartadas as incongruências, foi um movimento importante devido à sua repercussão internacional. $\mathrm{O}$ conhecimento edificado e cristalizado pelo colonizador a respeito dos povos africanos é deslegitimado, abrindo espaço para que a Literatura - representada por autores como Mia Couto, Paulina Chiziane, Pepetela, José Eduardo Agualusa, Ruy Duarte de Carvalho, entre outros - reconstruísse a história desse povo marcado pelas guerras e pela escravidão.

Dentre tantos autores importantes para esse processo de retorno às raízes e busca pela identidade africana, Ruy Duarte de Carvalho tem sido, ainda, o menos 
estudado. Talvez isso seja consequência do grau de complexidade de sua escrita, que, inclusive, questiona o fazer literário: “O que há de ser preciso para escrever, em primeiro lugar, senão achar que vale a pena porque tem destinatário? E para contar uma estória, que outra única e suficiente razão poderá haver senão vontade de a contar, de contar coisas?" (CARVALHO, 2007, p. 24).

O que observamos, tanto na obra Vou lá visitar pastores, quanto em Os papéis do inglês, é um discurso narrativo que apresenta uma nova interpretação da realidade nacional angolana a partir dos anos 70, para além das cristalizações do passado, provocando uma sensação de estranhamento através da modificação da paisagem, da forma discursiva e da ótica que não a dominante, seja ela nacional ou estrangeira.

O estranhamento causado pela escrita de Duarte é o que a torna ainda mais instigante. A ficção é construída por meio das informações antropológicas e experiências etnográficas vividas pelo narrador em suas viagens. Os caminhos percorridos pelo narrador/autor são múltiplos e não se limitam ao espaço geográfico e seus sujeitos, mas vão desde os questionamentos sobre a escrita até questões políticas de denúncia:

\footnotetext{
Eu andava por este sudoeste à procura de pessoas a tratar com elas, a tentar entendêlas nas suas razões, como inserem o que de facto fazem e o que pensam na desconcertante cena nacional que é a nossa. Por detrás dessa diligência havia também, sem dúvida, a paixão do deserto, e disso constava igualmente, e muito, aproveitar estes desvios para ver as gazelas, e exultar quando as encontrava pelo caminho, e parar o tempo que fosse preciso enquanto se mantinham ao alcance da minha exaltação, da emoção que me circula ao vê-las. (CARVALHO, 2007, p.104)
}

$\mathrm{O}$ excerto mostra o posicionamento ideológico/discursivo do autor frente à realidade angolana com que se deparava. $\mathrm{O}$ seu objetivo principal era as pessoas: saber o que pensavam e sentiam diante daquele cenário político do qual faziam parte, sem descartar sua beleza e exuberância. E a imagem da paisagem, 
no contexto desta errância parece fundir-se ao sujeito como estratégia de autopreservação de suas memórias e das tradições orais. Essa inter-relação do sujeito com o lugar, segundo Gaston Bachelard, trata-se do "espaço vivido. E vivido não em sua positividade, mas com todas as parcialidades da imaginação" (BACHELARD, 1998, p. 19). Ruy Duarte se inscreve nesse cenário como porta-voz desse "outro", narrando suas vivências num ritmo ora poético, ora cinematográfico.

O pastor que está ali, o da minha legítima invenção, também não sabe nada de Bachelard nem de fenomenologias, bem entendido. Mas ele sabe com certeza muito melhor que eu que é entre a terra, o espaço (território) e a água que tudo se joga na vida dele, comum, quotidiana, verdadeira. Ele fala-me com grande precisão nos capins e nas ramas que a terra dá, e onde as há e em que tempo, e quando é que convém que o gado as coma, do sal que ocorre aqui e só tem mais é muito para lá, da água que o gado bebe e é preciso tratar quando é a das pedras, porque choveu e é água nova, vilandava, e exige, para não fazer mal nem às pessoas nem aos animais, que uma mão de tyinbanda a purifique e abra. (CARVALHO, 1999, p.122).

O conhecimento, fruto da tradição oral, transmitido de maneira simples e singela através dos tempos, é o que basta para aqueles pastores. Eles vivem, sobrevivem, num mundo ainda marcado pelas desolações de constantes guerras, externas e internas. Ruy Duarte capta as sutilezas da simplicidade dessas pessoas, revelando seus motivos para estarem no mundo. Conforme Inocência Mata (2003), a nova literatura africana opta por representar a alteridade, despertando vozes e memórias que na utopia político-social não tinham lugar.

Para compreendermos como se processa a relação de Ruy Duarte de Carvalho com a construção das narrativas Vou lá visitar pastores (1999) e Os papéis do inglês (2007) veremos que a antropologia é o suporte, a base onde o autor constrói a ficção realista. Essas obras estão intrinsecamente interligadas, pois, em ambas, Duarte relata sua experiência de viagem pelo território Kuvale, que se estende para sul passando além do meridiano de Namibe (a antiga Moçâmedes) até as margens do Kunene. Outro fato interessante é que a obra $O s$ 
papéis do inglês parece se tratar de uma continuidade de Vou lá visitar pastores, pois, além de Ruy Duarte percorrer os mesmos caminhos, também retoma alguns personagens, como seu companheiro de deambulações Paulino.

Sendo Paulino um personagem real, que se instala na obra apenas como um guia contratado pelo antropólogo para conduzi-lo na viagem pelo deserto, sua existência não parece ter grande relevância, inicialmente, no contexto geral da obra. "Acompanhado pelo meu assistente Paulino e pelo seu sobrinho Gregório". (CARVALHO, 1999, 104). Mas, aos poucos, os laços entre ele e o antropólogo vão se estreitando, então parece que, ao contar a história do Inglês e sua relação com o Ganguela do Coice, Ruy Duarte está descrevendo sua própria relação com Paulino, seu companheiro de viagens. Contrariando todas as convenções hierárquicas e sociais, o Inglês, um respeitável antropólogo, se encantou com a música tradicional tocada no kissange pelo Ganguela, assim como este se encantou pelo som que saia do violino do Inglês.

A música foi o elemento que aproximou dois mundos tão distantes e opostos, causando uma alteração no panorama social, que via essa proximidade como inconcebível: "Uma importante alteração ao programa viria a dar-se quando, na estação seguinte, o Inglês passou a vir acompanhar, na senzala, os solos de kissange do Ganguela, surdina morosa em noites de lua e frias" (CARVALHO, 2007, p.78). A relação que une essas histórias é a capacidade de ouvir o outro. O Paulino, assim como seu avô (o Ganguela do Coice) inserido em seu contexto possui um conhecimento de valor inestimável, mas para que a história exista, é preciso alguém para ouvir.

O protagonismo de Paulino fica evidente em Os papéis do Inglês, pois nesse estágio sua existência é historicamente reconhecida pela história de seus antepassados, iniciada com seu avô, o Ganguela da história do Inglês. Nisso é revelada a relação de seu povo com as tradições orais. E sua relação com o autor 
se estreita, pois a busca pelos papéis os torna cúmplices ao compartilharem histórias, sonhos e frustrações.

Disso se constrói a narrativa de Ruy Duarte, da relação com o outro. Por meio do olhar sensível e despretensioso do autor, temos condições de conceber esse outro como um sujeito que tem muito a nos ensinar. Tudo isso em uma escrita que se apropria da Literatura e da Antropologia para criar algo completamente híbrido, mas legitimamente fascinante. Esse processo pode ser compreendido, segundo François Laplantine, da seguinte maneira:

O antropólogo, que realiza uma experiência nascida do encontro do outro, atuando como uma metamorfose de si, é frequentemente levado a procurar formas narrativas (romanescas, poéticas e, mais recentemente, cinematográficas) capazes de expressar e transmitir o mais exatamente possível essa experiência. (LAPLANTINE, 2007, p. 174)

A experiência de Duarte nasce de sua relação com o outro, como descreve Laplantine, e isso o impulsiona a criar formas narrativas capazes de expressar essa experiência. No entanto, o autor tem plena consciência das ambiguidades que permeiam o universo literário, e questiona essa convenção, como podemos ver ainda nas primeiras páginas de Os papéis do inglês:

Vou ter que contar-me, tratar-me, pois, enquanto personagem dessa história. E essa então será, comigo a actuar lá dentro e a primeira inscrita nela, a tal estória que tenho para contar-te. E quem narra não há-de ter, ele também, que dar-se a contar? Dito assim dá para entender onde quero chegar? Ou é por demais directo, excessivo, para caber na narração? (CARVALHO, 2007, p. 36).

Observamos que uma das estratégias criativas de Ruy Duarte consiste no provocante diálogo com o leitor, como podemos observar no trecho acima. $\mathrm{O}$ autor aguça a curiosidade do leitor por meio dos pontos de interrogação e reticências que permeiam as obras. Vai tecendo a narrativa repleta de digressões e reflexões críticas e filosóficas que funcionam como um tipo de ritual de encantamento que envolve o leitor, transformando-o numa espécie de cúmplice. 
Apesar de sabermos que há um suposto interlocutor para quem Duarte se dirige, é possível perceber que este também é um recurso discursivo do autor, pois este interlocutor é o motivo para que a narrativa seja produzida com métodos não convencionais: gravação de cassetes em Vou lá visitar pastores e escrita de e-mails em Os papéis do inglês. Este método de ter alguém (personagem secundário) para quem contar a história também é escolhido por Guimarães Rosa em Grande Sertão: Veredas, porém em Rosa o recurso é o diálogo direto entre Riobaldo e um interlocutor anônimo.

A ficção, em Ruy Duarte, não existe como simples fruto da imaginação do autor adaptada à paisagem, mas surge da experiência real e vivida entre ele e as pessoas, a natureza, as tradições, a cultura. Com isso, seu discurso singular acaba se tornando uma escrita híbrida em que as personagens, o espaço e o tempo são reais. Porém, percebemos que a história contada é reconfigurada pela lente do poeta antropólogo, que, mais do que relatar fatos, conta a história do povo Kuvale por meio de um olhar sensível e emocionado. Assim, o contexto discursivo da fíç̧ão de Ruy Duarte de Carvalho desconstrói a visão estereotipada da África e busca despertar as "vozes e memórias que na utopia² político-social não tinham lugar." (MATA, 2003, p.59). Ainda segundo a autora:

o contexto discursivo dessas metaficções historiográficas representa possibilidades de leituras do passado, expressões de reinterpretação para (...) moldá-lo às exigências das interpretações eficazes e iluminar segmentos sociais, ideias e eventos históricos antes na opacidade. (MATA, 2003, p. 60).

Nesse contexto, Ruy Duarte produziu estratégias para poder se comunicar com o espaço, por vezes restrito, da literatura. Nos seus inclassificáveis livros, a posição do etnógrafo como escritor (poeta e ficcionalista) é permanentemente tensionada e problematizada pelo método etnográfico usado por ele. Porém, sua

\footnotetext{
${ }^{2}$ Essa geração da utopia pode ser definida, segundo Pepetela, como "uma elite intelectual de causar inveja a qualquer país africano. Elite citadina, transitando tranquilamente da cultura europeia para a africana, acasalandoas com sucesso, num processo que vinha de séculos." (PEPETELA, 1992, p.305).
} 
escrita não se afasta, ideologicamente, dos objetivos literários preconizados por outros tantos escritores em Angola e Moçambique: dar voz àqueles que viviam na opacidade, representá-los, como lembra Inocência da Mata no trecho acima.

$\mathrm{O}$ autor sutilmente mostra em suas obras que quem conta uma história dificilmente se manterá isento. E o resultado sempre será uma ficção, pois sofre a influência interpretativa de quem escreve. Em relação a isso, o autor faz uma reflexão muito pertinente no final do primeiro capítulo de Os papéis do inglês:

\begin{abstract}
Na versão do Galvão, a morte do Inglês ocorre com arma de fogo, mas isso pode muito bem corresponder, julgo, a uma opção sua enquanto narrador, mais conforme, talvez, e segundo o seu critério, ao perfil de um aristocrata, tal como a motivação directa do crime, por ele atribuída a uma intempestiva reação do Inglês a insinuações torpes do Grego acerca de sua aversão a mulheres brancas, Da mesma forma que eu, a deter-me agora nesta estória, haveria de introduzir muita perturbação e muita invenção minhas na versão das coisas. É isso que vai acontecer?...Depende... Tenho que ver primeiro o que estará a passar-se por aqui. (CARVALHO, 2007, p.18)
\end{abstract}

É sobretudo pelos caminhos da autoficção que Ruy Duarte se posiciona como sujeito ético, não a ética específica de cada um dos campos disciplinares por que transita em sua obra, mas a ética do sujeito que escreve, a ética do escritor. Assim, ele põe em evidência o sujeito antropológico descrito por James Clifford (2011) no texto "Sobre a autoridade etnográfica". Para Clifford o etnógrafo se vale de estratégias discursivas que o conduzem ao campo literário da ficção, quando digressões e divagações de diversas ordens fazem o argumento antropológico ser rapidamente deslocado e perdido de vista. Desse modo, essas estratégias fazem a subjetividade surgir no nível do discurso antropológico e relativizam sua autoridade tradicional. Isso pode ser observado no capítulo "Giraul”, começo de uma descrição sobre a parte norte do território Kuvale:

A parte norte do território kuvale é de alguma forma excêntrica em relação à incidência maior do meu inquérito e das minhas experiências, tanto a recente quanto a remota, da infância. Mas no ano passado e no ano anterior andei por ali. De uma das 
vezes fui até Lucira e flecti depois para o interior, pela Mahandya. Aí atravessei o rio Carunjamba, para alcançar o Xingo. Estava a chover com força, corria água, mas dava ainda passagem. Quando mais à frente atingi o rio seguinte, o Inamandan-do, aí já não dava a voltei para trás, arrepiei caminho apenas para constatar que o Carunjamba tinha enchido também, entretanto. Fiquei dez dias retido entre as duas torrentes e só consegui sair dali quando achei que ia dar se recorresse ao processo de meter o carro na peúgada de uma manada de bois. Revolvem a areia e a lama do fundo, enquanto atravessam, e deixam mais firme o leito do rio. Com tracção às quatro rodas e aceleração certa consegues sair, e é a maneira de escapar a tanta água acumulada por toda parte e a toda a sorte de cobras e lagartos que em tais períodos da estação saem dos abrigos para refazer os ciclos que hã-de devolver mais tarde, novamente, à secura, ao frio e ao sono. Fugi literalmente dali e nem os magníficos bandos de humbihumbi que todas as tardes cruzavam o céu chuvoso, azul cobalto, em direcção ao Leste, me puderam evitar uma áspera crise pessoal, angústias de antropólogo, de nacional, de andarilho sem-eira-nembeira bloqueado no espaço e nas dobras do tempo, enredado nas malhas da sua própria deambulação (Carvalho, 2000, p. 75).

O autor pouco a pouco emerge da narrativa, passando por descrições essencialmente poéticas como "os magníficos bandos de humbi-humbi", "o céu chuvoso, azul cobalto". E, como se todos os caminhos conduzissem ao seu próprio autoconhecimento, chega a uma enigmática "áspera crise pessoal", que traz o sujeito do conhecimento antropológico para a superfície do texto. E, descrevendo-se como um personagem angustiado, à semelhança dos sujeitos do seu próprio conhecimento, "enredado nas malhas da sua própria deambulação", acaba por se autoficcionalizar.

Também fica claro na passagem de Vou lá visitar pastores que, apesar das evidentes dificuldades enfrentadas no trabalho antropológico, o autor nunca desistiu de seguir o caminho que traçou para si. Tampouco deixou de revelar as ambiguidades acadêmicas geradas por políticas pouco preocupadas com a educação, em Angola:

Eu não valia mesmo nada se aferido nos termos da prosperidade, do poder, da influência que definem por inteiro a afirmação pessoal e os estatutos em Angola, (...) E o facto de me dizer professor universitário só confirmava que em Angola a Universidade também não valia nada, caso contrário alguma coisa havia eu próprio de valer. (CARVALHO, 2007, p. 107). 
A trajetória de Ruy Duarte revela um autor que transita em diferentes discursos, mas permanece fiel à sua ideologia. Percorre os caminhos da ficção e da realidade, da verdade e da mentira, da certeza e da incerteza; fazendo desse trânsito entre discursos e pessoas o grande objetivo de sua vida. Podemos dizer, então, que o projeto de vida que o autor traça para si mesmo está diretamente associado à vida daqueles pastores, no deserto da Namíbia. Ruy Duarte quis estar lá: ver, sentir, entender como eles compreendiam e superavam as divergências de um passado colonial ao qual ainda sofrem consequências. Clifford Geertz afirma que:

A capacidade do antropólogo de nos fazer levar a sério o que diz tem menos a ver com uma aparência factual, ou com um ar de elegância conceitual, do que com sua capacidade de nos convencer de que o que eles dizem resulta de haverem realmente penetrado numa outra forma de vida (...) de realmente haverem, de um modo ou de outro, "estado lá". (GEERTZ, 2009, p. 15).

A afirmação de Geertz não parece se aplicar ao antropólogo Ruy Duarte de Carvalho, pois o que ele nos transmite em sua obra não se trata de convencimento, mas é a possibilidade de enxergar o "Outro" através das lentes da sua própria percepção. Ruy Duarte não representa o antropólogo que penetra em outra cultura, mas um sujeito que se mistura, sente e se envolve de tal maneira que conseguimos ver e ouvir o "Outro" a partir de sua leitura. Isso pode ser percebido claramente nas palavras do próprio autor, publicado no artigo ${ }^{3}$ intitulado "Uma espécie de habilidade autobiográfica":

E julgo, chegado a esta altura da vida, não poder deixar de ter que entender que o mundo, por toda a parte e não só aqui, se urde e se produz recorrendo sempre, ou quase sempre, ao uso e ao abuso da boa-fé dos outros. Temo não conseguir nunca chegar, mesmo velhinho, a conformar-me com isso e a tornar-me no sujeito bem acabado, dissimulado, pirata, adaptável e finalmente adaptado que nunca, durante toda a vida, consegui ser. (CARVALHO, 2010).

\footnotetext{
${ }^{3}$ Publicado no site http://www.buala.org em 12/08/2010 e, conforme referências do site, retirado da Editora Cotovia.
} 
Por tudo isso, percorrer os caminhos do poeta/antropólogo Ruy Duarte de Carvalho é mais do que fazer uma leitura antropológica de um determinado grupo, é vê-los como sujeitos que possuem um grande conhecimento, transmitido por muitas gerações ancestrais, e que corre o risco de desaparecer. Com Ruy Duarte a visão estereotipada do africano exótico, subjugado pelo branco, é desconstruída para dar lugar a outro tipo de imagem. Nela reconhecemos o valor da diferença, do sujeito que, inserido em seu contexto, está mais habilitado para contar sua própria história que qualquer outro. Ruy Duarte percebeu tudo isso e, inconformado com as injustiças históricas impostas aos africanos, fez mais do que estudá-los: além de ouvi-los deu sentido às suas histórias.

\section{REFERÊNCIAS}

CLIFFORD, James. A experiência etnográfica: Antropologia e Literatura no século XX.

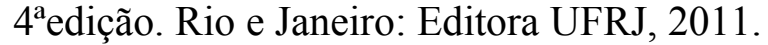

BACHELARD, Gaston. A poética do espaço. São Paulo: Martins Fontes, 1998.

CARVALHO, Ruy Duarte de. Vou lá visitar pastores. Rio de Janeiro: Gryphus, 1999. . Os papéis do inglês. São Paulo: Companhia das Letras, 2007.

- Uma espécie de habilidade autobiográfica. BUALA: cultura africana contemporânea. 2010. Disponível em http://www.buala.org/pt/ruy-duarte-de-carvalho/umaespecie-de-habilidade-autobiografica Consulta em 15/08/2013.

GEERTZ, Clifford. Obras e Vidas: O antropólogo como autor. $3^{\text {a }}$ edição. Rio de Janeiro: Editora UFRJ, 2009.

HISSA, Carlos Eduardo Viana. A mobilidade das fronteiras: inserções da geografia na crise da modernidade. Belo Horizonte: UFMG, 2002. 
MATA, Inocência. A condição pós-colonial das literaturas africanas: algumas diferenças e convergências e muitos lugares-comuns. _In Contatos e Ressonâncias: Literaturas de Língua Portuguesa. Belo Horizonte: PUC Minas, 2003.

PEPETELA. A Geração da Utopia. Rio de Janeiro: Nova Fronteira, 2000. 